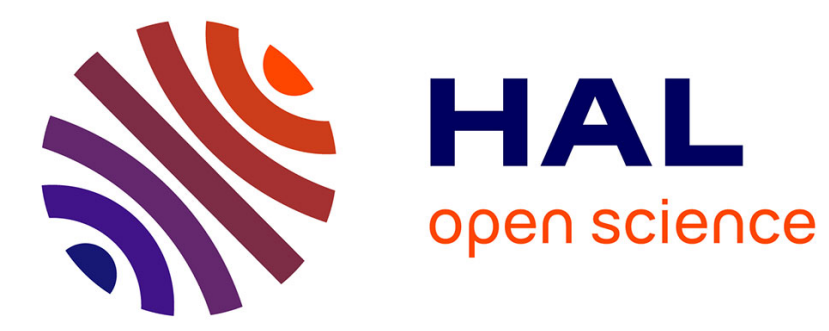

\title{
Thermodynamic investigation of yield-stress models for amorphous polymers
}

J Richeton, Said Ahzi, Loïc Daridon

\section{To cite this version:}

J Richeton, Said Ahzi, Loïc Daridon. Thermodynamic investigation of yield-stress models for amorphous polymers. Philosophical Magazine, 2007, 87 (24), pp.3629-3643. 10.1080/14786430701381162 . hal-00513838

\section{HAL Id: hal-00513838 \\ https://hal.science/hal-00513838}

Submitted on 1 Sep 2010

HAL is a multi-disciplinary open access archive for the deposit and dissemination of scientific research documents, whether they are published or not. The documents may come from teaching and research institutions in France or abroad, or from public or private research centers.
L'archive ouverte pluridisciplinaire HAL, est destinée au dépôt et à la diffusion de documents scientifiques de niveau recherche, publiés ou non, émanant des établissements d'enseignement et de recherche français ou étrangers, des laboratoires publics ou privés. 


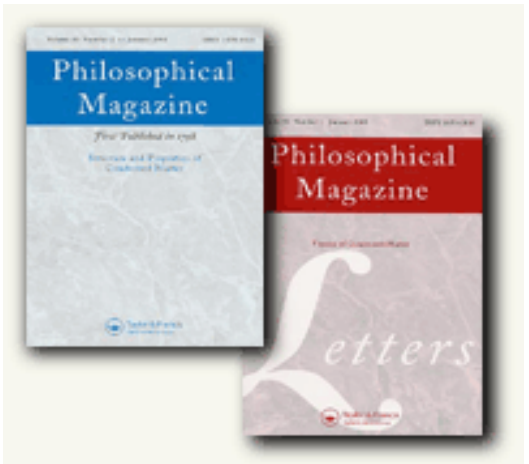

\section{Thermodynamic investigation of yield-stress models for amorphous polymers}

\begin{tabular}{|r|l|}
\hline Journal: & Philosophical Magazine \& Philosophical Magazine Letters \\
\hline Manuscript ID: & TPHM-06-Jun-0219 \\
\hline Journal Selection: & Philosophical Magazine \\
\hline Date Submitted by the & 21 -Jun-2006 \\
\hline Complete List of Authors: & $\begin{array}{l}\text { Richeton, J; Universite Louis Pasteur, IMFS } \\
\text { Ahzi, Said; University Louis Pasteur, IMFS } \\
\text { Daridon, L; Universite de Montpellier II, LMGC }\end{array}$ \\
\hline Keywords: & $\begin{array}{l}\text { mechanical behaviour, polymers, thermodynamics, plastic } \\
\text { deformation }\end{array}$ \\
\hline Keywords (user supplied): & yield stresse, amorphous polymers \\
\hline &
\end{tabular}

\section{ScholarONE \\ Manuscript Central}




\title{
Thermodynamic investigation of yield-stress models for amorphous polymers
}

\author{
J. Richeton, S. Ahzi ${ }^{*}$ and L. Daridon ${ }^{+}$ \\ Institut de Mécanique des Fluides et des Solides - UMR 7507 \\ Université Louis Pasteur, 2 Rue Boussingault, 67000 Strasbourg, France
}

\begin{abstract}
A thermodynamic study of the yield process in amorphous polymers is proposed to investigate four yield theories: the Eyring model and its linearized form, the cooperative model and the Argon model. For a poly(methyl methacrylate) (PMMA) and a polycarbonate (PC), the corresponding apparent activation volumes and apparent activation energies are calculated and compared for a wide range of temperatures and strain rates. In the case of the cooperative model, we show that the secondary molecular relaxation is a key parameter in the explanation of the specific mechanical behaviour of glassy polymers at low temperatures and at high strain rates. For the three other models, thermodynamic inconstancies were found and these are discussed.

\footnotetext{
* Corresponding author. Tel +33-3902-42952; fax +33-3886-14300; e-mail: ahzi@imfs.u-strasbg.fr.

+Present address: Laboratoire de Mécanique et de Génie Civil - UMR 5508, Université de Montpellier II
} 


\section{Introduction}

The stress-strain response of amorphous polymers is known to be dependent on temperature and on strain rate. In particular, the yield stress obeys thermally activated processes. Many molecular theories have been proposed for the prediction of the yield stress in the case of amorphous polymers [1-15]. Most of these models give an acceptable description of the yield stress, but they are either unable to account for the dramatic increase of the yield stress at higher strain rates or are not valid through the glass-transition temperature region [16]. Recently, a new formulation of the cooperative model $[17,18]$ has been shown to give excellent results for a wide range of strain rates and temperatures, including the high strain rates and the glass-transition region.

The purpose of the present paper is to study and compare the thermodynamic properties associated with four different yield-stress models: the two forms of Eyring's models, Argon's model, and the cooperative models. This step will be helpful for an understanding of the temperature and strain-rate limitations of the models. The thermodynamic formalism of the yield stress for amorphous polymers is originally contained in the work of Lefebvre, Escaig and co-workers [19-21] according to the concept of apparent activation volume and apparent activation energy. This formalism could be applied to any yield model. However, an analytical form for the apparent activation volume and energy could be derived only for the four predicted models. Numerical study of the thermodynamic formalism for other models such as the Robertson model [3] and the Ree-Eyring formulation $[2,4-9]$ are undoubtedly of interest but this is out of the scope of the present paper. In addition, we note that the pressure can be included in each of the analysed models, as was done by Ward [22] for the Eyring models, by Boyce et al. [23] for the Argon model and by Richeton et al. [18] for the cooperative model. However, for the sake of simplicity and since we are 


\section{Thermodynamic analysis of the models}

\subsection{Background}

Lefebvre, Escaig and co-workers [19-21] introduced a thermodynamic development for the yield stress relating strain rate, applied stress and temperature at comparable structural states. They focused their interest on the apparent (or operational) activation volume $V_{0}$ and on the apparent activation energy $\Delta H_{0}$. Expressions for $V_{0}$ at a fixed temperature and structure and that for $\Delta H_{0}$ at fixed yield stress and temperature are given by:

$$
\left\{\begin{aligned}
V_{0} & =k T\left(\frac{\partial \ln \dot{\varepsilon}}{\partial \sigma_{y}}\right)_{T, \text { struct. }} \\
\Delta H_{0} & =k T^{2}\left(\frac{\partial \ln \dot{\varepsilon}}{\partial T}\right)_{\sigma_{y}, \text { struct. }}
\end{aligned}\right.
$$

where $k$ is the Boltzmann constant, $T$ is the absolute temperature, $\dot{\varepsilon}$ is the strain rate and $\sigma_{y}$ is the yield stress.

\subsection{Application to the Eyring model}


Eyring's model derives from the formal development of the transition-state theory [1]. The resulting strain rate is classically given by:

$$
\dot{\varepsilon}=\dot{\varepsilon}_{0}^{E} \exp \left(-\frac{\Delta H^{E}}{k T}\right) \sinh \left(\frac{\sigma_{y} V^{E}}{2 k T}\right)
$$

where $\dot{\varepsilon}_{0}^{E}$ is a constant pre-exponential strain rate, $\Delta H^{E}$ is an activation energy and $V^{E}$ is an activation volume.

Using equations (1) and (2), the operational activation volume of the Eyring model is derived as:

$$
V_{0}^{E}=\frac{V^{E}}{2} \frac{1}{\tanh \left(\sigma_{y} V^{E} / 2 k T\right)}
$$

We propose to rewrite this equation as a function of temperature and strain rate by solving Eq.

(2) for $\sigma_{y} V^{E} / 2 k T$ and given that for $x>0,\left(\tanh \left(\sinh ^{-1}(1 / x)\right)\right)^{-1}=\sqrt{1+x^{2}}$. The activation volume is then reduced to a handier form:

$$
V_{0}^{E}=\frac{V^{E}}{2} \sqrt{1+\left(\frac{\dot{\varepsilon}_{0}^{E}}{\dot{\varepsilon}} \exp \left(-\frac{\Delta H^{E}}{k T}\right)\right)^{2}}
$$

In a similar way, the operational activation energy is given by: 


$$
\Delta H_{0}^{E}=\Delta H^{E}-\frac{\sigma_{y} V^{E}}{2} \frac{1}{\tanh \left(\sigma_{y} V^{E} / 2 k T\right)}
$$

According to Eq. (3), this can also be written as

$$
\Delta H_{0}^{E}=\Delta H^{E}-\sigma_{y} \cdot V_{0}^{E}
$$

Here, we notice that the operational activation energy is composed of two separate entities. The first represents the activation energy in absence of stress and the second contributes to the reduction of the total energy barrier arising from the presence of stress.

\subsection{Application to the linearized Eyring model}

Eyring's equation is frequently presented in the following linearized form:

$$
\dot{\varepsilon}=\dot{\varepsilon}_{0}^{L E} \exp \left(-\frac{\Delta H^{L E}-\sigma_{y} V^{L E}}{k T}\right)
$$

where all the parameters have the same meaning as in Eq. (2). This form is simply obtained by replacing the hyperbolic function of Eq. (2) by an exponential under the condition $\sigma_{y} V^{E} / 2 k T>1$. As a matter of fact, the original Eyring parameters and the linearized ones are linked as follow:

$$
\dot{\varepsilon}_{0}^{L E}=\frac{\dot{\varepsilon}_{0}^{E}}{2} \quad \Delta H^{L E}=\Delta H^{E} \quad V^{L E}=\frac{V^{E}}{2}
$$


For this model, the operational activation volume is found to be independent of the temperature and the strain rate:

$$
V_{0}^{L E}=V^{L E}
$$

For the operational activation energy, we obtain:

$$
\Delta H_{0}^{L E}=\Delta H^{L E}-\sigma_{y} \cdot V^{L E}
$$

Since $V_{0}^{L E}=V^{L E}$, this equation is simply the classical form of the operational activation energy as given in Eq. (6). Moreover, according to Eqs. (7) and (10), it can be shown that the apparent activation energy is proportional to the temperature:

$$
\Delta H_{0}^{L E}=k T \ln \left(\frac{\dot{\varepsilon}_{0}^{L E}}{\dot{\varepsilon}}\right)
$$

\subsection{Application to the cooperative model}

The cooperative model was originally developed by Fotheringham and Cherry [13,14], who modified the Eyring equation by postulating that yielding involves a cooperative motion of polymer chain segments. They also assumed that yield stress has to be corrected by an internal stress, $\sigma_{i}$. The resulting model is an Eyring-like equation, where the hyperbolic sine function is raised to an $n$-th power. 


$$
\dot{\varepsilon}=\dot{\varepsilon}^{*}(T) \sinh ^{n}\left(\frac{\left(\sigma_{y}-\sigma_{i}(T)\right) V^{C}}{2 k T}\right)
$$

where $\dot{\varepsilon}^{*}(T)$ is a characteristic thermally activated strain rate, $n$ is a material parameter used to depict the cooperative movement of the chain segments, and $\sigma_{i}(T)$ is the internal stress; all other parameters have been previously defined. Based on the work of Povolo and coworkers [24,25] and of Brooks et al [26], a recent development by Richeton et al. [17] allowed a derivation of the temperature dependence of $\dot{\varepsilon}^{*}(T)$ and $\sigma_{i}(T)$ :

$$
\left\{\begin{array}{c}
\dot{\varepsilon}^{*}(T)=\dot{\varepsilon}_{0}^{C} \exp \left(-\frac{\Delta H_{\beta}}{k T}\right) \\
\sigma_{i}(T)=\sigma_{i}(0)-m T
\end{array}\right.
$$

where $\dot{\varepsilon}_{0}^{C}$ is a constant pre-exponential strain rate, $\Delta H_{\beta}$ is the $\beta$ activation energy, $\sigma_{i}(0)$ is the athermal internal yield stress and $m$ is a material parameter roughly equal to $\sigma_{i}(0) / T_{g}$ ( $T_{g}$ being the glass-transition temperature). The relation between yielding and the segmental mobility associated with secondary relaxation of polymer chains has also been highlighted by Yee and co-workers [27,28] and by Halary and co-workers [29,30].

In addition, as was previously done by other authors [3,5,31], the cooperative model can be extended through the glass-transition region [17]. In this domain, the resulting yield stress has to vanish to zero with respect to the Williams-Landel-Ferry (WLF) equation [32]. In the rubbery region, the expressions of $\dot{\varepsilon}^{*}(T)$ and $\sigma_{i}(T)$ are expressed as [17]: 


$$
\left\{\begin{array}{c}
\dot{\varepsilon}^{*}\left(T \geq T_{g}\right)=\dot{\varepsilon}_{0}^{C} \exp \left(-\frac{\Delta H_{\beta}}{k T_{g}}\right) \exp \left(\frac{\ln 10 \times c_{1}^{g}\left(T-T_{g}\right)}{c_{2}^{g}+T-T_{g}}\right) \\
\sigma_{i}\left(T \geq T_{g}\right)=0
\end{array}\right.
$$

where $c_{1}^{g}$ and $c_{2}^{g}$ are the WLF parameters and all other parameters have been defined previously. For the determination of $\sigma_{i}\left(T \geq T_{g}\right)$, we simply consider a vanishing internal stress above $T_{g}$. This assumption renders the proposed model for the yield stress to be noncontinuous through the glass-transition temperature region. Moreover, it is postulated here that the glass transition occurs for a single temperature, even though it is universally known that it occurs over a range of temperatures.

In line with the results of Povolo and co-workers [24,25], the operational activation volume for the cooperative model is given by:

$$
V_{0}^{C}=\frac{n V^{C}}{2} \frac{1}{\tanh \left(\left(\sigma_{y}-\sigma_{i}\right) V^{C} / 2 k T\right)}
$$

With the same development of Section 2.2, it can be shown that:

$$
V_{0}^{C}=\frac{n V^{C}}{2} \sqrt{1+\left(\frac{\dot{\varepsilon}^{*}(T)}{\dot{\varepsilon}}\right)^{2 / n}}
$$

This expression is valid through the glass transition with the corresponding expressions for $\dot{\varepsilon}^{*}(T)$. Moreover, by extrapolating Eq. (16) at $0 \mathrm{~K}, V_{0}^{C}$ tends towards $n V^{C} / 2$. This can be 
easily understood since $\dot{\varepsilon}^{*}\left(T<T_{g}\right)$ tends towards zero when the temperature goes to zero. This result is valid as long as $\dot{\varepsilon}$ is different from zero. This critical value of $n V^{C} / 2$ for $V_{0}^{C}$ might correspond to the least size of the activation volume as mentioned by Nanzai et al. [33]. We also note that $\dot{\varepsilon}^{*}(T)$ increases with increasing temperature below, as well as above, $T_{g}$. According to Eq. (16), at low strain rates or high temperatures, the value of $V_{0}^{C}$ is much higher than that at low temperatures or high strain rates. Even if there are still doubts of what clearly represents the activation volume, it is established that molecular yield processes are both intermolecular and intramolecular [28]. A recent paper on the modelling of the temperature and strain-rate dependence of yield stress in a binary Lennard-Jones glass [34] shows that a cooperative motion in glassy solids is necessary for yield to occur because a single molecule (or a polymer segment in our case) cannot move without dragging its nearest neighbours in motion. This observation of Varnik et al. [34] is a molecular kinematics that is directly obtained from simulations and not a priori assumed. Therefore the more chain segments involved cooperatively in the yield process, the more is the chain slipping facilitated, and the less force is required to stretch the polymer. This remark is in agreement with what can be found in the work of Yee and co-workers [27,28]. These authors proposed that the segments of chains that are already mobile become even more mobile with the application of stress. The increase of the activation volume results in the reduction of the interactions between chains and thereby reducing the resistance for chains to slide relative to one another. This effect can be linked to a lubrication (OK?) on a molecular level. By facilitating lateral slipping of chain segments, large scale sliding of chains is feasible, thus increasing the activation volume.

Concerning the operational activation enthalpy, it can be shown, for temperatures below $T g$ and using the cooperative model, that [25]: 


$$
\Delta H_{0}^{C}\left(T<T_{g}\right)=\Delta H_{\beta}-V_{0}^{C} \cdot\left(\sigma_{y}-\sigma_{i}(0)\right)
$$

As for the Eyring model, the apparent activation enthalpy given by Eq. (17) is composed of two separate entities. The first represents the activation energy in absence of all stresses and the second contributes to the reduction of the total energy barrier owing to the presence of an effective stress, $\sigma_{y}-\sigma_{i}(0)$. As an expression for $\Delta H_{0}\left(T>T_{g}\right)$, we found:

$$
\Delta H_{0}^{C}\left(T \geq T_{g}\right)=\frac{\ln 10 \times c_{1}^{g} c_{2}^{g} k T^{2}}{\left(c_{2}^{g}+T-T_{g}\right)^{2}}-V_{0}^{C} \cdot \sigma_{y}
$$

Eq. (18) is similar to Eq. (17). According to our proposed modelling for temperatures above $T_{g}$, the apparent energy for viscoelastic relaxation is considered above $T_{g}$ as shown in Eq. (18) instead of $\Delta H_{\beta}$ below $T_{g}$ in Eq. (17). This viscoelastic energy has already been used in the Robertson [3] and Nanzai [33,35] theories where yielding is associated with the structural change of the glass into a liquid-like structure. Although the structural change in Roberston's theory has been supported experimentally near the glass-transition region [36], we have to mention that the form of the viscoelastic energy was given by Robertson without the square exponents. If the Roberston model is implemented with the square exponents in the expression of the viscoelastic energy as originally given by Ferry [32], the results obtained for the yield stress are completely out of range [37].

\subsection{Application to the Argon model}


Argon developed a kink-pair nucleation model that takes into account the intermolecular resistance to shear yielding $[10,11]$. The model is generally given in term of shear but it can also be considered in term of uniaxial deformation:

$$
\dot{\varepsilon}=\dot{\varepsilon}_{0}^{A} \exp \left(-\frac{s_{0} V^{A}}{k T}\left(1-\left(\frac{\sigma_{y}}{s_{0}}\right)^{5 / 6}\right)\right)
$$

Where $s_{0}$ is an athermal yield strength and all other symbols have the same meaning as in previous paragraphs. The activation volume $V^{A}$ is found to be dependent on the geometrical considerations of the kink model.

According to the previous developments, the apparent activation volume for the Argon model can be expressed as:

$$
V_{0}^{A}=\frac{5 V^{A}}{6}\left(\frac{s_{0} V^{A}}{k T \ln \left(\dot{\varepsilon}_{0}^{A} / \dot{\varepsilon}\right)}\right)^{1 / 5}
$$

This expression is of great interest since it indicates that the activation volume $V_{0}^{A}$ is proportional to $T^{-1 / 5}$. In other words, it signifies that $V_{0}^{A}$ decreases with increasing temperature. This observation implies that the physics of kinks used by Argon is not thermodynamically acceptable since it is widely established that activation volumes have to increase with rising temperature. In this result, one can also explain why Argon's model does not work at high temperature since the activation volume has been found to greatly increase in the glass-transition region [33]. As another remark, the strain-rate dependence of $V_{0}^{A}$ 
according to Argon's model is the opposite of that found for the cooperative model (an increasing strain rate has to diminish the activation volume).

Concerning, the apparent activation energy, it can be shown that:

$$
\Delta H_{0}^{A}=k T \ln \left(\frac{\dot{\varepsilon}_{0}^{A}}{\dot{\varepsilon}}\right)
$$

The temperature and strain rate dependence of $\Delta H_{0}^{A}$ is exactly the same for $\Delta H_{0}^{L E}$ (the one found for the linearized Eyring model). This equation does not consider kink physics anymore. As a matter of fact, the Argon model is very close to the linearized Eyring formula [38]. Indeed, by roughly approximating the 5/6 exponent of Eq. (19) to 1, the latter form for the energy is exactly one of the linearized Eyring's equation with:

$$
\Delta H^{A}=s_{0} V^{A}
$$

In other words, the good fit provided by the Argon model [11] is not due to physics of kinks but rather to the use of a thermally activated process as is the case with the Eyring models.

\section{Results and discussion}

\subsection{Preliminary discussion}


As it is the case for the yield stress, the operational activation volume and activation enthalpy are also temperature and strain-rate dependent. For two polymers, a poly(methyl methacrylate) (PMMA) and a polycarbonate (PC), we propose to make a comparison of these three quantities according to the different models. For the high strain rates, the curves do not take into account the temperature rise generated by the elastic deformation. If it is true that dramatic temperature changes occur at high strain rates, it has to be remembered that the major part of the adiabatic heating is usually dissipated during the plastic deformation and not during the elastic deformation $[39,40]$. All the model parameters used for the modelling can be found in Table 1 and reference to one of our previous works [18].

\subsection{Yield stress results}

Figure 1 shows, for PMMA and PC, a comparison between the strain-rate dependence for the compressive yield stress for the different models presented in this study and some experimental data from Richeton et al. [18]. For both polymers, the cooperative model is the only one to show good agreement with the data at the very high strain rates. There is no major difference between the three other models, which present a linear dependence versus the decimal logarithm of the strain rate. The increase of the yield stress at high strain rates can be accounted for by a restriction of the $\beta$ movements of the polymer chains. An increasing strain rate diminishes the molecular mobility of the chains by preventing their relaxation. A similar increase of the yield stress is observed for temperatures close to the secondary relaxation temperature, $T_{\beta}$.

The temperature dependence of the compressive yield stress can be seen in Figure 2. A significant increase at about $0^{\circ} \mathrm{C} / 50^{\circ} \mathrm{C}$ is observed for the yield stress of PMMA. Depending on the frequency, these temperatures are in the range of the secondary relaxation temperature 
of PMMA $\left(10^{\circ} \mathrm{C}\right.$ at $\left.1 \mathrm{~Hz}\right)$. For PC, the yield stress also begins to exhibit the appearance of the secondary transition at $-100^{\circ} \mathrm{C}$. This dramatic increase of yield stress at about $-100^{\circ} \mathrm{C} /-150^{\circ} \mathrm{C}$ has been experimentally observed and attributed to the presence of the $\beta$ transition $[42,43]$. This can easily be understood since below $T_{\beta}$ the secondary molecular movements are restricted and thus the polymer chains are stiffer. In comparison with other models, only the cooperative model is able to describe successfully this phenomenon. The case of PMMA is particularly explicit since the secondary transition occurs nearly at room temperature. Concerning the $T>T_{g}$ temperatures, the extension of the cooperative model gives satisfactory results in comparison to the experimental data. The linearized Eyring and Argon models are completely out of range since the extrapolation of these two models for the high temperatures give negative values for the yield stress. However the Eyring model has a slightly different behaviour since the presence of the sinh function make this model tend towards zero value for high temperatures. For PC, we have to mention that the sharp drop of the yield stress predicted by the cooperative model in the glass-transition domain is due to the fact that the internal stress $\sigma_{i}$ is not continuous through the glass transition. Nevertheless, the agreement between the modelling and experimental results remains far better than for the other models. For PMMA, no such drop is observed since the numerical value of the internal stress, as defined by Eq. (13), is almost zero for $T=T_{g}$.3.3. Apparent activation volume

Figure 3 represents the apparent activation volume, $V_{0}^{C}$, obtained for the cooperative model for PMMA and PC. For both polymers, $V_{0}^{C}$ increases exponentially with temperature and decreases with an increasing strain rate. These results for PMMA are quantitatively in agreement with the experimental results of Lefebvre and Escaig [21]. As mentioned earlier, at the very low temperatures, $V_{0}^{C}$ tends towards a constant value, which corresponds to the least 
size of the activation volume, $n V^{C} / 2$. We believe that the parameters $n$ and $V$ are coupled since none of them can separately be related to a physical quantity. It has also been suggested that the activation volume may correlate to the scale of the secondary relaxation [28]. This remark is consistent with Eq. (16) where the secondary relaxation is taken into account, being quantitatively represented by the activation energy $\Delta H_{\beta}$ in the expression for $\dot{\varepsilon}^{*}(T)$. On Figure 3, this phenomenon is characterized by an exponential increase of the activation volume for temperatures close to the secondary transition temperature. Moreover, as was already mentioned, the secondary transition is itself strain-rate dependent: an increase of strain rate will shift the value of $T_{\beta}$ to higher temperatures. Then the activation volume increases more dramatically above $T_{g}$. This statement is in agreement with Nanzai's theory [33,35] where it is believed that, near $T_{g}$, yielding can involve up to 150 monomers. The breakage in the curves at the glass transition can be explained by the fact that we have considered the glass transition as a single temperature.

Figure 4 makes a comparison of the temperature dependence of the apparent activation volume for the different models presented in this study for a strain rate of $0.001 \mathrm{~s}^{-1}$. The cooperative model is the only one to present a significant temperature dependence for $V_{0}$. As for the linearized Eyring model, the Eyring model has almost no temperature dependence. However, by considering a sinh function instead of an exponential one, this model presents an increase of $V_{0}$ at the high temperatures. This result is a pure numerical artifact; it has no physical meaning. For the Argon model, as was mentioned previously, the temperature dependence is erroneous from a physical point of view. All these preceding observations will still be valid for strain rates different from $0.001 \mathrm{~s}^{-1}$. Apart from the cooperative model, the apparent activation volume derived from the other models is in total contradiction with polymer physics since it can nearly be considered independent of temperature and strain rate. In Table 2, a comparison of the intrinsic model parameters shows that all activation volumes 
are of the order of $10^{-28} \mathrm{~m}^{3}$. This value is roughly equal to the volume of a statistical link in solution [44], supporting the fact that the least critical size of $V_{0}^{C}$ may be equal to the volume of a single statistical link. Concerning the actual value of the apparent activation volume, it is pretty hard to draw any conclusion. As was reported in section 2.5 , the activation volume actually groups all possible chain displacement into a single parameter, including both intermolecular and intramolecular processes. The key to solving this problem is to identify clearly the cooperative character of the yield process. Here, we can also mention the atomistic approach of Mott et al. [45] for the kinematics of plastic deformation in glassy polymers. These authors found via molecular simulation that the estimated sizes of the plastically relaxing clusters are very large in comparison with the atomic or molecular segment dimensions. They defined the yield process as a complex and cooperative collection of bond rotations among the backbone segments.

\subsection{Apparent activation energy}

Figure 5 represents the apparent activation energy obtained for the cooperative model for PMMA and PC. In the glassy region, $\Delta H_{0}^{C}$ bears the stamp of the secondary relaxation. For PMMA, the predictions are in agreement to what can be found in the literature [20]. As expected, an increasing strain rate will activate a decrease of $\Delta H_{0}^{C}$. The extrapolated value of $\Delta H_{0}^{C}$ at $0 \mathrm{~K}$ tends to zero. This statement allows us to recover the fact that $V_{0}^{C}$ tends towards $n V^{C} / 2$ by solving Eq. (17) at $0 \mathrm{~K}$ (starting from Eq. (12), it can be shown that $\left.\sigma_{y}(0)=\sigma_{i}(0)+2 \Delta H_{\beta} / n V^{C}\right)$. Then, according to Eqs. (17) and (18), $\Delta H_{0}^{C}$ goes through a change of regime at the glass transition. Figure 6 shows for the cooperative model that the two energies are different of about one order of magnitude. Contrary to what Nanzai et al. [33] 


\section{Conclusions}

postulated, we do not have a symmetrical behaviour of the activation energy with respect to $T_{g}$. We think that the structural transition theories (transition of the glass into liquid-like structures during yielding) $[3,33,35]$ are not suitably able to describe the complexity of the yield process (especially at low temperatures and high strain rates). The main reason is that they do not take into account the secondary relaxation. This is also the case with the three other models of this study.

There is no difference between the apparent activation energies of the two Eyring modelsand the Argon model. For these three models, $\Delta H_{0}$ presents a simple linear dependence on temperature without any physical transitions. Furthermore, for these models, the values of the activation energy as given in Table 1 cannot be related to any physical process - contrary to the case for the cooperative model.

In this paper, we have made a thermodynamic comparison of different yield stress models involving a thermally activated rate process. The following comments are the significant results from this work on amorphous polymers:

1- From a thermodynamic point of view, there is no major difference between the Eyring model and its linearized form.

2- The physics of kinks used in Argon's theory is not thermodynamically consistent. The diminution of the apparent activation volume with increasing temperature is not physically acceptable. Furthermore, we have shown that the Argon model and the two forms of the Eyring model present virtually the same physical limitations with regard to the 
temperature and strain-rate response of the yield stress, apparent activation volume and apparent activation energy.

3- For the prediction of the yield stress in a wide range of strain rates and temperatures, the apparent activation volume and the apparent activation energy have to bear the stamp of the secondary relaxation, as is the case for our formulation of the cooperative model. The augmentation of the yield stress at low temperatures or high strain rates can be accounted for by a diminution of the $\beta$ movements.

4- The structural transition theories of yield $[3,33,35]$ solely based on the use of the WLF equation can in no way describe the yield process at low temperatures and high strain rates.

\section{Acknowledgments}

The authors wish to thank the "French National Centre for Scientific Research (CNRS)" and the "Région Alsace" for providing financial support to the $\mathrm{PhD}$ thesis of $\mathrm{J}$. Richeton.

\section{References}

[1] Eyring H. J Chem Phys 1936;4:283.

[2] Ree T, Eyring H. J Appl Phys 1955;26:793.

[3] Robertson RE. J Chem Phys 1966;44:3950.

[4] Bauwens-Crowet C, Bauwens JC, Homès G. J Polym Sci A2 1969;7:735.

[5] Bauwens-Crowet C, Bauwens JC, Homès G. J Polym Sci A2 1969;7:1745.

[6] Bauwens JC. J Polym Sci Pol Sym 1971;33:123.

[7] Bauwens-Crowet C, Bauwens JC, Homès GJ. Mater Sci 1972;7:176.

[8] Bauwens JC. J Mater Sci 1972;7:577. 
[9] Bauwens-Crowet C. J Mater Sci 1973;8:968.

[10] Argon AS. Phil Mag 1973;28:839.

[11] Argon AS, Bessonov MI. Polym Engng Sci 1977;17:174.

[12] Bowden PB, Raha S. Phil Mag 1974;29:149.

[13] Fotheringham D, Cherry BW. J Mater Sci 1976;11:1368.

[14] Fotheringham D, Cherry BW. J Mater Sci 1978;13:951.

[15] Spathis G. J Mater Sci 1997;32:1943.

[16] Richeton J, Ahzi A, Daridon L., Rémond Y. J Phys IV 2003;110:39.

[17] Richeton J, Ahzi A, Daridon L., Rémond Y. Polymer 2005;46:6035.

[18] Richeton J, Ahzi A, Vecchio KS, Jiang FC, Adharapurapu RR. accepted by Int J Sol Struct (2005).

[19] Haussy J, Cavrot JP, Escaig B, Lefebvre JM. J Polym Sci Pol Phys 1980;18:311.

[20] Lefebvre JM, Escaig B. J Mater Sci 1985;20:438.

[21] Escaig B. Polym Engng Sci 1984;24:737.

[22] Ward IM. J Mater Sci 1971;6:1397.

[23] Boyce MC, Parks DM, Argon AS. Mech Mater 1988;7:15.

[24] Povolo F, Hermida EB. J Appl Polym Sci 1995;58:55.

[25] Povolo F, Schwartz G., Hermida EB. J Appl Polym Sci. 1996;61:109.

[26] Brooks NWJ, Duckett RA, Ward IM. J Rheol 1995;39:425.

[27] Xiao C, Jho JY, Yee AF. Macromolecules 1994;27:2761.

[28] Chen LP, Yee AF, Moskala EJ. Macromolecules 1999;32:5944.

[29] Brulé B, Halary JL, Monnerie L. Polymer 2001;42:9073.

[30] Rana D, Sauvant V, Halary JL. J Mater Sci 2002;37:5267.

[31] Roetling JA. Polymer 1965;6:615. 
[32] Ferry JD. Viscoelastic Properties of Polymers, 3rd ed. New-York: John Wiley \& Sons; 1980.

[33] Nanzai Y, Konishi T, Ueda S. J Mater Sci 1991;26:4477.

[34] Varnik F, Bocquet L, Barrat JL, J Chem Phys 2004;120:2788.

[35] Nanzai Y. Polym Eng Sci 1990;30:96.

[36] Xu Z, Jasse B, Monnerie L. J Polym Sci Pol Phys 1989;27:355.

[37] Richeton J. PhD Thesis 2005, University Louis Pasteur (Strasbourg I).

[38] Ward IM. Mechanical Properties of Solid Polymers, 2nd ed. New-York: John Wiley \& Sons; 1983.

[39] Arruda EM, Boyce MC. Int J Plasticity 1993;9:697.

[40] Rittel D. Mech Mater 1999;31:131.

[41] Halary JL, Oultache AK, Louyot JF, Jasse B, Sarraf T, Muller R. J Polym Sci Pol Phys 1991;29:933.

[42] Boyer RF. Polym Engng Sci 1968;8:161.

[43] Kastelic JR, Baer EJ. Macromol Sci Phys 1973;B7:679.

[44] Haward RN, Thackray G. P Roy Soc Lond A 1968;302:453.

[45] Mott PH, Argon AS, Suter UW, Phil Mag A 1993;67:931. 
Table 1. Model parameters for PMMA and PC. The WLF parameters were taken from Refs. [41] and [32].

\begin{tabular}{|c|c|c|c|}
\hline Models & Parameters & PMMA & for PC \\
\hline Eyring & $\begin{array}{c}\dot{\varepsilon}_{0}^{E}\left[\mathrm{~s}^{-1}\right] \\
\Delta H^{E}[\mathrm{~kJ} / \mathrm{mol}] \\
V^{E}\left[\mathrm{~m}^{3}\right]\end{array}$ & $\begin{array}{c}4.23 \times 10^{24} \\
178 \\
6.76 \times 10^{-28} \\
\end{array}$ & $\begin{array}{c}1.38 \times 10^{21} \\
224 \\
3.83 \times 10^{-27} \\
\end{array}$ \\
\hline $\begin{array}{l}\text { Linearized } \\
\text { Eyring }\end{array}$ & $\begin{array}{c}\dot{\varepsilon}_{0}^{L E}\left[\mathrm{~s}^{-1}\right] \\
\Delta H^{L E}[\mathrm{~kJ} / \mathrm{mol}] \\
V^{L E}\left[\mathrm{~m}^{3}\right]\end{array}$ & $\begin{array}{c}2.11 \times 10^{24} \\
178 \\
3.38 \times 10^{-28}\end{array}$ & $\begin{array}{c}6.89 \times 10^{20} \\
224 \\
1.92 \times 10^{-27}\end{array}$ \\
\hline Argon & $\begin{array}{c}\dot{\varepsilon}_{0}^{A}\left[\mathrm{~s}^{-1}\right] \\
s_{0}[\mathrm{MPa}] \\
V^{A}\left[\mathrm{~m}^{3}\right] \\
\Delta H^{A}=s_{0} \cdot V^{A}[\mathrm{~kJ} / \mathrm{mol}]\end{array}$ & $\begin{array}{c}1.92 \times 10^{24} \\
1131 \\
2.60 \times 10^{-28} \\
177\end{array}$ & $\begin{array}{c}1.06 \times 10^{21} \\
205 \\
2.01 \times 10^{-27} \\
205\end{array}$ \\
\hline Cooperative & $\begin{array}{c}\dot{\varepsilon}_{0}^{C}\left[\mathrm{~s}^{-1}\right] \\
\Delta H_{\beta}[\mathrm{kJ} / \mathrm{mol}] \\
V^{C}\left[\mathrm{~m}^{3}\right] \\
\sigma_{i}(0)[\mathrm{MPa}] \\
m[\mathrm{MPa} / \mathrm{K}] \\
n\end{array}$ & $\begin{array}{c}7.46 \times 10^{15} \\
90 \\
5.14 \times 10^{-29} \\
190 \\
0.47 \\
6.37\end{array}$ & $\begin{array}{c}8.69 \times 10^{12} \\
40 \\
5.16 \times 10^{-29} \\
145 \\
0.24 \\
5.88\end{array}$ \\
\hline & $\begin{array}{c}\operatorname{Tg}[\mathrm{K}] \\
c_{1}^{g} \\
c_{2}^{g}\left[{ }^{\circ} \mathrm{C}\right]\end{array}$ & $\begin{array}{c}378 \\
9 \\
36\end{array}$ & $\begin{array}{c}413 \\
17.44 \\
51.60\end{array}$ \\
\hline
\end{tabular}

Table 2. Comparison of the activation volumes

\begin{tabular}{c|c|c} 
Parameters & Values for PMMA & Values for PC \\
\hline$V^{E} / 2\left[\mathrm{~m}^{3}\right]$ & $3.38 \times 10^{-28}$ & $1.92 \times 10^{-27}$ \\
\hline$V^{L E}\left[\mathrm{~m}^{3}\right]$ & $3.38 \times 10^{-28}$ & $1.92 \times 10^{-27}$ \\
\hline$V^{A}\left[\mathrm{~m}^{3}\right]$ & $2.60 \times 10^{-28}$ & $2.01 \times 10^{-27}$ \\
\hline$n V^{C} / 2\left[\mathrm{~m}^{3}\right]$ & $1.64 \times 10^{-28}$ & $1.52 \times 10^{-28}$ \\
\hline $\begin{array}{c}\text { Volume of a statistical link } \\
\text { in solution }\left[\mathrm{m}^{3}\right], \text { after }[44]\end{array}$ & $9.10 \times 10^{-28}$ & $4.82 \times 10^{-28}$
\end{tabular}


Fig. 1. Strain rate dependence of the yield stress for a PMMA and a PC tested under uniaxial compression at a temperature of $25^{\circ} \mathrm{C}$.
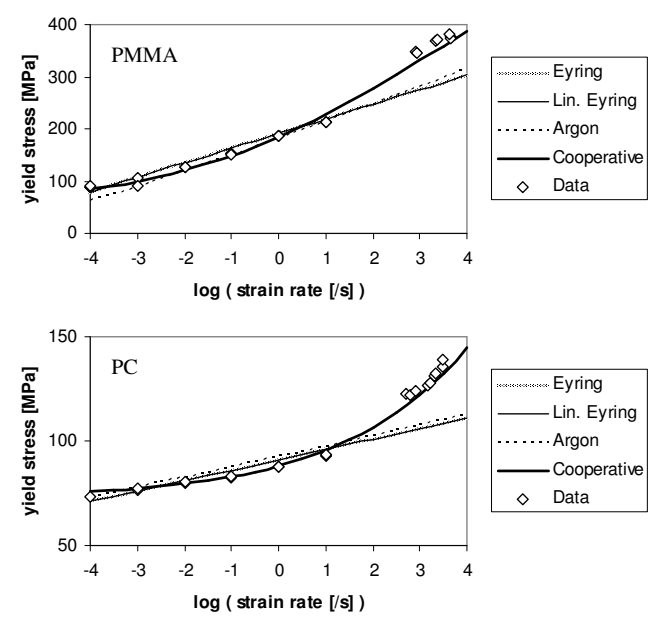

Fig. 2. Temperature dependence of the yield stress for a PMMA and a PC tested under uniaxial compression at a strain rate of $0.01 \mathrm{~s}^{-1}$.
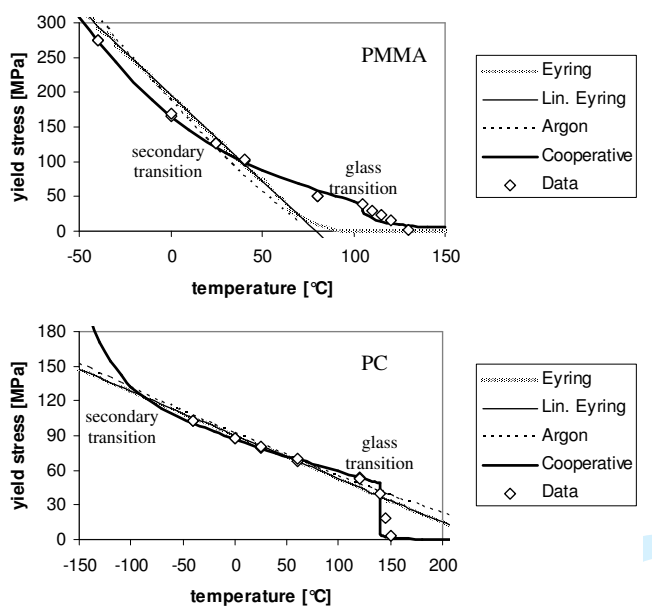
Fig. 3. Influence of temperature and strain rate on the apparent activation energy of the cooperative model for a PMMA and a PC tested under uniaxial compression.
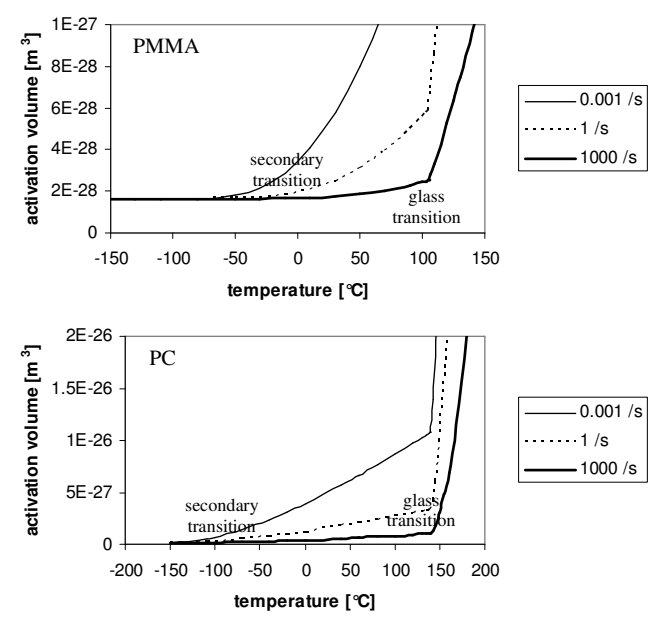

Fig. 4.Comparison of the apparent activation volumes for a PMMA and a PC tested under uniaxial compression at a strain rate of $0.001 \mathrm{~s}^{-1}$.
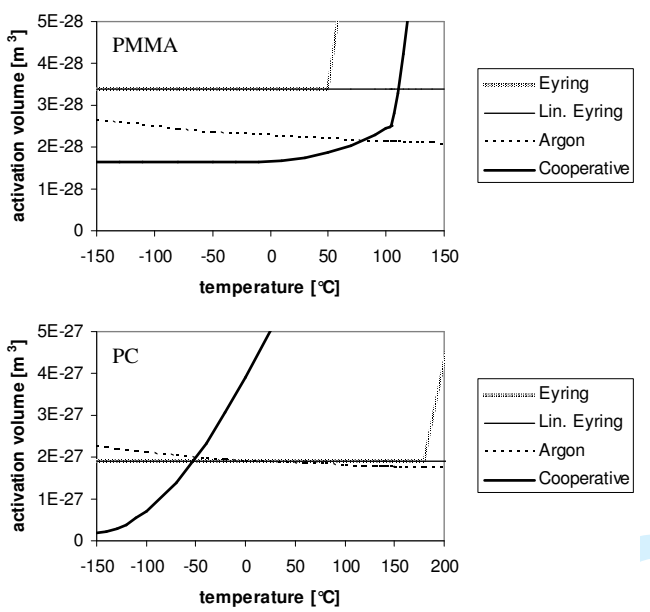
Fig. 5. Influence of temperature and strain rate on the apparent activation energy of the cooperative model for a PMMA and a PC tested under uniaxial compression.
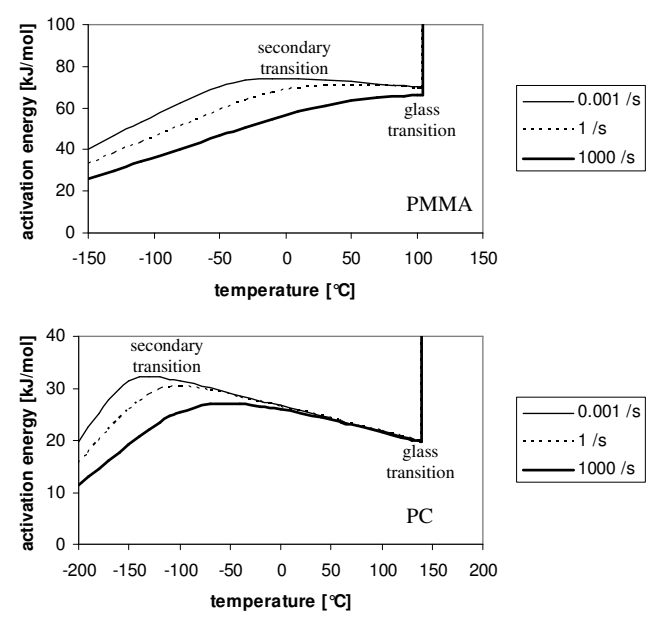

Fig. 6. Comparison of the different apparent activation energies for a PMMA and a PC tested under uniaxial compression at a strain rate of $0.001 \mathrm{~s}^{-1}$.
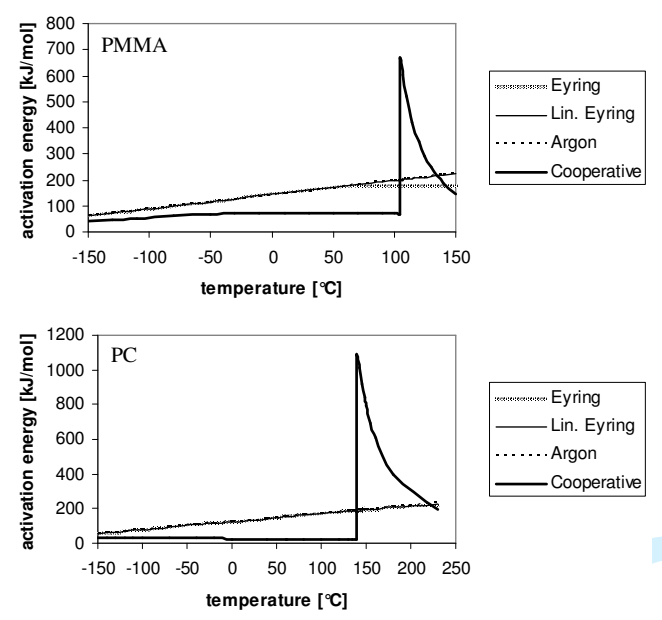